\title{
Dopamine D2 receptor gene polymorphisms and externalizing behaviors in children and adolescents
}

Osmar Henrique Della Torre ${ }^{1,5^{*}}$ D, Lúcia Arisaka Paes ${ }^{1}$, Taciane Barbosa Henriques², Maricilda Palandi de Mello², Eloisa Helena Rubello Valler Celeri ${ }^{1}$, Paulo Dalgalarrondo ${ }^{1}$, Gil Guerra-Júnior ${ }^{3,4}$ and Amilton dos Santos-Júnior ${ }^{1}$

\begin{abstract}
Background: Dopamine is involved in several cerebral physiological processes, and single nucleotide polymorphisms (SNP) in the dopamine D2 receptor gene (DRD2) have been associated with numerous neurological and mental disorders, including those involving alterations in cognitive and emotional processes.

Methods: The aim of this study was to evaluate the association between the SNPs c.957C > T (rs6277) and c.-585A > G (rs 1799978) in the DRD2 gene and behavioral characteristics of children and adolescents based on an inventory of the Child Behavior Checklist (CBCL). Children and adolescents between 8 and 20 years old who were clinically followed-up were genotyped for the SNPs C.957C > T and c.-585A > G, and related to data of the CBCL/6-18 scale assessment performed with the help of caregivers. The chi-squared test was used to assess the differences in the frequencies of the $C$ and $T$ alleles in the polymorphism c.957C > T and of the $A$ and $G$ alleles in the polymorphism c.-585A > G with respect to the grouped $\mathrm{CBCL}$ scores at a significance level of 5\%. Multiple logistic regression models were performed, to control whether sex and/or ethnicity could influence the results.

Results: Eighty-five patients were assessed overall, and the presence of the $T$ allele (C/T and T/T) of DRD2 c.957C > T polymorphism was found to be significantly associated with the occurrence of defiant and oppositional problems and with attention and hyperactivity problems. There were no associations detected with polymorphism DRD2 c.585A > G polymorphism. Both SNPs were in Hardy-Weinberg-equilibrium.

Conclusions: Although the findings of this study are preliminary, due to its small number of participants, the presence of T allele (C/T, T/T) in c.957C > T SNP was associated with difficulty in impulse control, self-control of emotions, and conduct adjustment, which can contribute to improving the identification of mental and behavioral phenotypes associated with gene expression.
\end{abstract}

Keywords: Genetic polymorphism, Dopamine, Behavior, c.957C > T polymorphism, c.-585A > G polymorphism

\section{Background}

The dopamine D2 receptor gene (DRD2), located at chromosome 11q23.1, is involved in several cerebral physiological processes, including behavior inhibition and externalizing conditions, i.e., aggression and symptoms such as oppositional defiance, conduct problems, and attention deficit/hyperactivity [1-7].

\footnotetext{
* Correspondence: dr.osmar.psiq@gmail.com; otorre@fcm.unicamp.br ${ }^{1}$ Department of Psychiatry - Faculty of Medical Sciences (FCM), State University of Campinas (Unicamp), Campinas, SP, Brazil

${ }^{5}$ Rua Tessália Vieira de Camargo, 126, Cidade Universitária Zeferino Vaz Campinas, São Paulo ZIP Code: 13083-887, Brazil

Full list of author information is available at the end of the article
}

The single nucleotide polymorphism (SNP) c.957C > T (rs6277) is located on the seventh exon of DRD2 gene at the 319 codon that codes a proline [8]. Individuals with $\mathrm{C} / \mathrm{C}$ homozygous genotypes, associated with a higher density of extrastriatal D2 receptors, were shown to be more efficient in inhibiting unwanted action tendencies and showed increased reward responsiveness after stress induction compared to $\mathrm{T} /$ - carriers $[5,9]$. The presence of the $\mathrm{T}$ allele is associated with a reduction of the translation and stability of the messenger RNA (mRNA), and with a reduction in protein synthesis by up to $50 \%$ in comparison with activity of the C allele [10-12].

(c) The Author(s). 2018 Open Access This article is distributed under the terms of the Creative Commons Attribution 4.0 International License (http://creativecommons.org/licenses/by/4.0/), which permits unrestricted use, distribution, and 
The functional consequence of SNP c.-585A $>$ G (rs1799978) is currently unknown; however, it is suspected to regulate the expression of the $D R D 2$ gene due to its location on the promoter region [13]. The G allele has been associated with conditions related to impulsiveness [14].

In this study, we tested the hypothesis that the $\mathrm{T}$ allele of the c.957C $>\mathrm{T}$ (rs6277) polymorphism and/or the $\mathrm{G}$ allele of the c.-585A $>\mathrm{G}$ (rs1799978) polymorphism are associated with the occurrence of externalizing behaviors among children and adolescents under psychiatric treatment.

\section{Methods}

This was a descriptive cross-sectional study, with a sample composed of patients attending the Psychiatric Outpatient Clinic of Children and Adolescents, Department of Medical Psychology and Psychiatry, Clinical Hospital and School of Medical Sciences, University of Campinas (Unicamp) from March 2014 to August 2015. The center provides a service that typically cares for severe cases, most of whom are under a regime of psychotropic drugs, requiring a more complex level of mental health attention than those receiving primary health care.

In addition to information about the use of medications and diagnoses registered on medical records, the inventory of the Child Behavior Checklist for the age range of 6-18 years old (CBCL/6-18) was used for qualification of the presence and severity of the mental and behavioral symptoms [15]. The CBCL/6-18 is a standardized questionnaire designed by Achenbach in 1991, answered by the parents or caregivers, which is used to assess the behaviors of children or adolescents [16] and was validated for application in the Brazilian population [17]. The CBCL/6-18 is widely recommended as one of the most effective tools for the qualification of parental responses related to childhood behavior [18]. Such an inventory provides a profile of behavioral and emotional problems in syndromic groups, but has not been validated as a diagnostic instrument $[18,19]$. As the CBCL/6-18 does not evaluate neurocognitive problems, individuals with severe or profound intellectual disability were not included in this study, because their behavioral symptoms would not be differentiable between those associated with intellectual disability itself and those due to other disruptive behavioral disorders. The emotional/behavior problem section of the CBCL/6-18 has 118 items [20]. The adult respondent has to attribute the following scores to each problem: 0 , not true; 1 , somewhat true or rare; and 2 , very true or very frequent over the last six months [17]. Analysis of the CBCL/6-18 scores was conducted with the software of the Achenbach System of Empirically Based Assessment [17], and the results were grouped into three kinds of profiles: syndrome-based scores, which evaluate symptoms for each of the main clusters of mental health problems; scales that mainly group psychological symptoms according to internalizing and externalizing dimensions; and scales consistent with DSM-IV scales [19]. The following DSM-oriented scales were used: "anxiety problems", "somatic problems", "attention deficit hyperactivity disorder problems", "opposition and challenging problems", and "conduct problems" [19].

The results obtained from the $\mathrm{CBCL} / 6-18$ responses from parents or other adult caregivers, and not the children/adolescents, were used to classify the children/adolescents into the following categories: "normal" (behavior scores $<67$, total scores $<60$ ), "borderline clinical range" (behavior scores 67-70, total scores 60-63), and "clinical range" (behavior scores $>70$, total scores $>63$ ) [19].

The genomic DNA samples were obtained from $8 \mathrm{~mL}$ of total peripheral blood collected in tubes with EDTA $(0.6 \mathrm{M}), \mathrm{pH} 8.0$ as anticoagulant. Genomic DNA was purified from peripheral leukocytes according to standard protocols by lysing with proteinase $\mathrm{K}$, extracting with phenol/chloroform, and precipitating with ethanol [21]. To determine genotypes for c.957C $>\mathrm{T}$ (rs6277) and c.-585A > G (rs1799978) in the DRD2 gene, realtime PCR using $\mathrm{TaqMan}^{\circ}$ allelic discrimination assay (Applied Biosystems, Foster City, CA - USA) and primers available from SNP Genotyping Assay (Applied Biosystems, Foster City, CA - USA) were used. The total volume for all reactions was $7 \mu \mathrm{l}$ containing TaqMan Genotyping PCR Master Mix 2X (3.5 $\mu \mathrm{l})$ and SNP Genotyping Assay 40X $(0.175 \mu \mathrm{l})$, MiliQ water $(2.325 \mu \mathrm{l})$ and $10 \mathrm{ng}$ of each genomic DNA $(1 \mu \mathrm{l})$. Reactions were performed in 96-well optical plates (0.1 ml MicroAmp, Applied Biosystems) and submitted to the following temperatures and cycles: a first cycle of 10 min denaturation at $95^{\circ} \mathrm{C}$ followed by 40 cycles of $15 \mathrm{~s}$ at $95^{\circ} \mathrm{C}$ and $1 \mathrm{~min}$ extension at $60{ }^{\circ} \mathrm{C}$. Amplification reactions were performed in a 7500 Fast Real-Time PCR System (Applied Biosystems). Validation studies demonstrate that the Applied Biosystems 7500 System SDS is a robust, reliable, and reproducible system for performing DNA quantification [22]. Data were recorded and analyzed using 7500 System Sequence Detection Software` (SDS).Descriptive and chi-square statistical analyses were carried out using SPSS version 22 (IMB Co., Armonk, NY, USA). For relevant associations, multiple logistic regression analyses were carried out using Stata/SE version 14.1 (StataCorp LP, College Station, TX, USA). They were performed to control whether the associations were due to sex or ethnicity differences. Each model of multiple logistic regression analysis used, as dependent variable, the emotional/behavioral problem evaluated by CBCL 6/18 which had significant statistical association with the presence/absence of the $\mathrm{T}$ allele of the rs6277 SNP of the $D R D 2$ gene. Sex, ethnicity and the presence/absence of the $\mathrm{T}$ allele itself were the independent variables. 
Hardy-Weinberg equilibrium was evaluated by the Haploview software (BROAD Institute) [23, 24] to determine if the allele frequencies of the SNPs assessed in the study population were balanced and therefore applicable for association studies. For the statistical analysis, the CBCL/ 6-18 results were grouped into two distinct groups of two categories each: in the first group, the results were compared between those without alterations ("normal") versus those with alterations ("borderline clinical range" plus "clinical range"); in the second group, the results were compared between those without alterations or with few alterations ("normal" plus "borderline clinical range") versus those with substantial alterations ("clinical range"). The chi-squared test was applied to evaluate the differences in the $\mathrm{C}$ and $\mathrm{T}$ allele frequencies for the polymorphism c.957C $>\mathrm{T}$ and in the $\mathrm{A}$ and $\mathrm{G}$ allele frequencies for the polymorphism c. $-585 \mathrm{~A}>\mathrm{G}$ in relation to the grouped scores of the CBCL/6-18. The significance level adopted was $5 \%$.

\section{Results}

This study comprised 85 patients with a mean age of $13.4 \pm 2.7$ years. Sixty-five patients $(76.5 \%)$ were male. The sample was composed of 61 (71.8\%) Caucasian individuals, 15 (17.6\%) bi-racial (African and Caucasian individuals), 8 (9.4\%) African individuals, and 1 (1.2\%) Asian individual. The majority of the CBCL/6-18 assessment respondents were women (84.7\%), 54 (75\%) of which were the biological mothers. The other respondents included fathers, grandparents, and shelter caregivers that accompanied the child or adolescent. Three participants had already been hospitalized in a psychiatric inpatient ward, due to severe disruptive behavior (one with 11 days of hospitalization, one with 14 days and the third with 17 days), but all of them had already been discharged by the time of the beginning of the study.

All patients were receiving risperidone therapy, and 19 patients $(22.7 \%)$ were on risperidone monotherapy. By the time of data collection, all participants were in psychiatric outpatient treatment for externalized psychopathological conditions in which risperidone may be utilized. Antidepressants were also involved in the treatment regimen of 46 (54.1\%) cases, followed by psychostimulants in 23 patients (27.1\%) and clonidine in 11 patients (12.9\%). Anticonvulsants, lithium, benzodiazepines, and other associated antipsychotics accounted for $17.6 \%$ (15 patients) of the total use of medicines. The medication had been given for a mean of $34.6 \pm 23.5$ months.

According to the clinical evaluation made by experienced psychiatrists and collected from the patients' medical records, the psychiatric syndromes were described as: disruptive/aggressive (42 patients, $49.4 \%$ ), hyperkinetic (35 patients, $41.2 \%)$, depressive $(29,34.1 \%)$, intellectual disability $(24,28.2 \%)$, autism $(20,23.5 \%)$, phobic-anxious $(17,20 \%)$, learning disturbances $(13,15.3 \%)$, and psychotic $(6,7.1 \%)$.

The DRD2 polymorphisms were in Hardy-Weinberg equilibrium [c.957C > T (rs6277) $p=0.4169$, c. $-585 \mathrm{~A}>\mathrm{G}$ (rs1799978) $p=0.246]$. Table 1 shows the genotypic distribution, sample allele frequencies, and minor allele frequencies (MAFs) of the SNPs for the study sample and the global population according to the 1000 Genomes Project and HapMap databases. The MAFs of the study population were highly similar to those of the global population for both polymorphic alleles.

Table 2 shows the genotypic distribution of the evaluated SNPs of the DRD2 gene, regarding sex, age, psychiatric diagnoses and use of psychopharmacological medications. No statistically significant associations were found $(p>0.05)$. Regarding the CBCL/6-18 results, the only significant associations between them and the polymorphisms were between the c.957C > T (rs6277) polymorphism and the occurrence of oppositional defiant disorders, attention problems, and hyperactivity, which are summarized in detail in Table 3. Figures 1 and 2 show the genotypic distribution of the rs6277 SNP (C/C, $\mathrm{C} / \mathrm{T}$ and $\mathrm{T} / \mathrm{T}$ ) regarding the $\mathrm{CBCL} / 6-18$ significant results. There were no significant associations for the SNP c. $-585 \mathrm{~A}>\mathrm{G}$ (rs1799978).

For challenging and oppositional problems according to DSM-IV, multiple logistic regression models were performed, to test whether the association of the presence of the T allele of the rs6277 SNP of the DRD2 gene with both oppositional problems and attention problems/ hyperactivity could be due to sex or ethnicity differences between groups (Table 4). The presence or absence of the $\mathrm{T}$ allele, regarding sex and ethnicity, is shown in Table 4. Sex and ethnicity had no statistical associations with any of the groups of symptoms studied (Table 4) and, after the multiple logistic regressions, the presence

Table 1 Genotypic distribution and allele frequencies of DRD2 gene polymorphisms

\begin{tabular}{|c|c|c|c|c|}
\hline SNP & Genotype & Allele frequency & $\begin{array}{l}\text { MAF }^{a} \text { of the } \\
\text { study population }\end{array}$ & MAF $^{a}$ from the global database \\
\hline rs6277 & $\begin{array}{l}\text { C/C } 43 \text { (50.6\%) } \\
\text { C/T } 37(43.5 \%) \\
\text { T/T } 5 \text { (5.9\%) }\end{array}$ & $\begin{array}{l}C=123(72.35 \%) \\
T=47(27.65 \%)\end{array}$ & $T=27.65 \%$ & $T=24.4 \%$ \\
\hline rs1799978 & $\begin{array}{l}\text { A/A } 66 \text { (77.6\%) } \\
\text { A/G } 19(22.4 \%)\end{array}$ & $\begin{array}{l}A=151(88.82 \%) \\
G=19(11.18 \%)\end{array}$ & $G=11.18 \%$ & $G=11.9 \%$ \\
\hline
\end{tabular}


Table 2 Genotypic distribution of the evaluated SNPS of the DRD2 gene, regarding demographic data, psychiatric diagnoses and use of psychopharmacological medications

\begin{tabular}{|c|c|c|c|c|c|}
\hline & \multicolumn{3}{|l|}{ rs6277 } & \multicolumn{2}{|l|}{ rs1799978 } \\
\hline & $\mathrm{C} / \mathrm{C}$ & $\mathrm{C} / \mathrm{T}$ & $\mathrm{T} / \mathrm{T}$ & $\mathrm{A} / \mathrm{A}$ & $A / G$ \\
\hline \multicolumn{6}{|l|}{ Sex } \\
\hline Female & $13(65 \%)$ & $6(30 \%)$ & $1(5 \%)$ & $15(75 \%)$ & $5(25 \%)$ \\
\hline Male & $30(46.2 \%)$ & $31(47.7 \%)$ & $4(6.2 \%)$ & $51(78.5 \%)$ & $14(21.5 \%)$ \\
\hline \multicolumn{6}{|l|}{ Age } \\
\hline $8-10$ years-old & $6(37.5 \%)$ & $8(50 \%)$ & $2(12.5 \%)$ & $12(75 \%)$ & $4(25 \%)$ \\
\hline $11-15$ years-old & $24(48 \%)$ & $23(46 \%)$ & $3(6 \%)$ & $39(78 \%)$ & $11(22 \%)$ \\
\hline More than 15 years-old & $13(68.4 \%)$ & $6(31.6 \%)$ & 0 & $15(78.9 \%)$ & $4(21.1 \%)$ \\
\hline \multicolumn{6}{|l|}{ Intelligence quotient (IQ) } \\
\hline Normal & $33(52.4 \%)$ & $27(42.9 \%)$ & $3(4.8 \%)$ & $49(77.8 \%)$ & $14(22.2 \%)$ \\
\hline Mild-Moderate intellectual disability & $10(45.5 \%)$ & $10(45.5 \%)$ & $2(9.1 \%)$ & $17(77.3 \%)$ & $5(22.7 \%)$ \\
\hline \multicolumn{6}{|l|}{ Psychiatric condition } \\
\hline Disruptive/aggressive & $20(47.6 \%)$ & $19(45.2 \%)$ & $3(7.1 \%)$ & $34(81 \%)$ & $8(19 \%)$ \\
\hline Hyperkinetic & $16(45.7 \%)$ & $16(45.7 \%)$ & $3(8.6 \%)$ & $24(68.6 \%)$ & $11(31.4 \%)$ \\
\hline Depressive & $15(51.7 \%)$ & $12(41.4 \%)$ & $2(6.9 \%)$ & $24(82.8 \%)$ & $5(17.2 \%)$ \\
\hline Autism & $14(70 \%)$ & $5(25 \%)$ & $1(5 \%)$ & $16(80 \%)$ & $4(20 \%)$ \\
\hline Phobic-anxious & $10(58.8 \%)$ & $6(35.3 \%)$ & $1(5.9 \%)$ & $13(76.5 \%)$ & $4(23.5 \%)$ \\
\hline Learning disturbances & $5(38.5 \%)$ & $7(53.8 \%)$ & $1(7.7 \%)$ & 7 (53.8\%) & $6(46.2 \%)$ \\
\hline Psychotic & $2(33.3 \%)$ & $4(66.7 \%)$ & 0 & $5(83.3 \%)$ & $1(16.7 \%)$ \\
\hline \multicolumn{6}{|l|}{ Psychiatric medication } \\
\hline Antipsychotics & $43(50.6 \%)$ & $37(43.5 \%)$ & $5(5.9 \%)$ & $66(77.6 \%)$ & 19 (22.4\%) \\
\hline Antidepressants & $26(56.5 \%)$ & 17 (37\%) & $3(6.5 \%)$ & $38(82.6 \%)$ & $8(17.4 \%)$ \\
\hline Psychostimulants & $8(34.8 \%)$ & $12(52.2 \%)$ & $3(13 \%)$ & $18(78.3 \%)$ & $5(21.7 \%)$ \\
\hline Clonidine & $5(45.5 \%)$ & $6(54.5 \%)$ & 0 & $10(90.9 \%)$ & $1(9.1 \%)$ \\
\hline Others & $6(40 \%)$ & $7(46.7 \%)$ & $2(13.3 \%)$ & $11(73.3 \%)$ & $4(26.7 \%)$ \\
\hline
\end{tabular}

${ }^{a}$ There were no individuals with the G/G genotype of the rs1799978 SNP of the DRD2 gene

of the $\mathrm{T}$ allele remained associated both with challenging and oppositional problems (odds ratio $=2.78[$ CI95\% $=1$. $15-6.71] ; p=0.023$ ) and, with less statistical significance, with attention problems and hyperactivity (odds ratio $=$ $2.69[$ CI95\% $=1.001-7.24] ; p=0.050)$ (Table 4).

\section{Discussion}

In the present study, the possible associations of the polymorphisms c.957C $>\mathrm{T} \quad$ (rs6277) and c. $-585 \mathrm{~A}>\mathrm{G}$ (rs1799978) of the DRD2 gene with the emotional/behavior problem section of the CBCL/6-18 were investigated; a significant association was detected between the polymorphism c.957C > T (rs6277) and the occurrence of oppositional defiant disorders, attention problems, and hyperactivity. The association remained after controlling for sex and ethnicity.

The allele frequency of the SNP c.957C > T (rs6277) was similar to that of the general population $[25,26]$. It

Table 3 Significant associations between the results of the CBCL/6-18 and the rs6277 polymorphism of the DRD2 gene

\begin{tabular}{|c|c|c|c|c|}
\hline & Presence of the $\mathrm{T}$ allele $(\mathrm{C} / \mathrm{T} \text { e } \mathrm{T} / \mathrm{T})^{*}$ & Absence of the $T$ allele $(\mathrm{C} / \mathrm{C})$ & $p$-value & $x^{2}$ \\
\hline \multicolumn{5}{|c|}{ Challenging and oppositional problems according to the DSM-IV } \\
\hline No alteration (0) & $14(35.9 \%)$ & $25(64.1 \%)$ & 0.022 & 5.265 \\
\hline With alteration ( 1 and 2 ) & $28(60.9 \%)$ & $18(39.1 \%)$ & & \\
\hline \multicolumn{5}{|c|}{ Attention problems and hyperactivity by the DSM-IV } \\
\hline Few alterations ( 0 and 1 ) & $26(42.6 \%)$ & $35(57.4 \%)$ & 0.046 & 3.983 \\
\hline Substantial alteration (2) & $16(66,7 \%)$ & $8(33,3 \%)$ & & \\
\hline
\end{tabular}

"There were no associations between the rs 1799978 polymorphism of DRD2 and any of the CBCL/6-18 results 


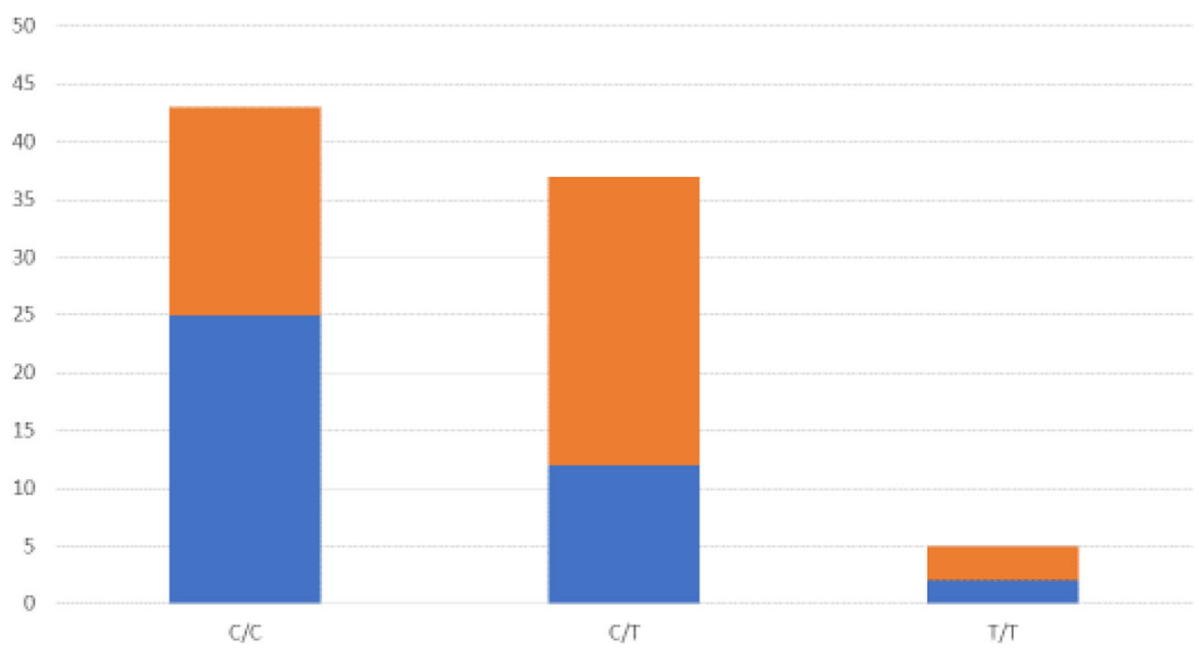

Fig. 1 Genotypic distribution of the c.957C>T (rs6277) SNP, regarding challenging and oppositional problems. Above: with alteration; Below: no alteration

is interesting to note that the genotype distributions of the African, Asian, and European populations differ from each other as well as from the population of the present study; in particular, in the Asian and African populations, the $\mathrm{T} / \mathrm{T}$ genotype is extremely rare $(6 \%)$ and there is a higher frequency of heterozygotes in the European population (54\%), indicating heterogeneity among these populations, and similarity between the Brazilian and Amerindian populations $[25,26]$. The allelic frequency of the SNP c.-585A > G (rs1799978) in the study population was similar to that of the general population, with a slightly higher MAF of the $\mathrm{G}$ allele in the global population $(11.9 \%$ vs. $11.2 \%)$ [26, 27].

Ethnicity did not have statistical influence in the logistic regression models. Moreover, Pena et al. in 2011 showed that the race of individuals in Brazil cannot be predicted from their genomic ancestry alone [28]. Understanding the heterogeneity and admixture of Brazilians within and between geographical regions has important clinical implications for the design and interpretation of clinical trials, practice of clinical genetics and genomic medicine, implementation of pharmacogenetic knowledge in drug prescriptions, and extrapolation of data from other, more homogeneous populations [28]. The admixture proportions vary greatly among Brazilian populations as well as across Latin America [29]. The pooled ancestry contributions in Brazil are reported to be 0.62 European, 0.21 African, and 0.17 Amerindian [29].

The results of the present study showed a higher frequency association amongst externalizing symptoms, which, according to Goodman, result in hyperactive, challenging, aggressive, or antisocial behaviors [30]. These

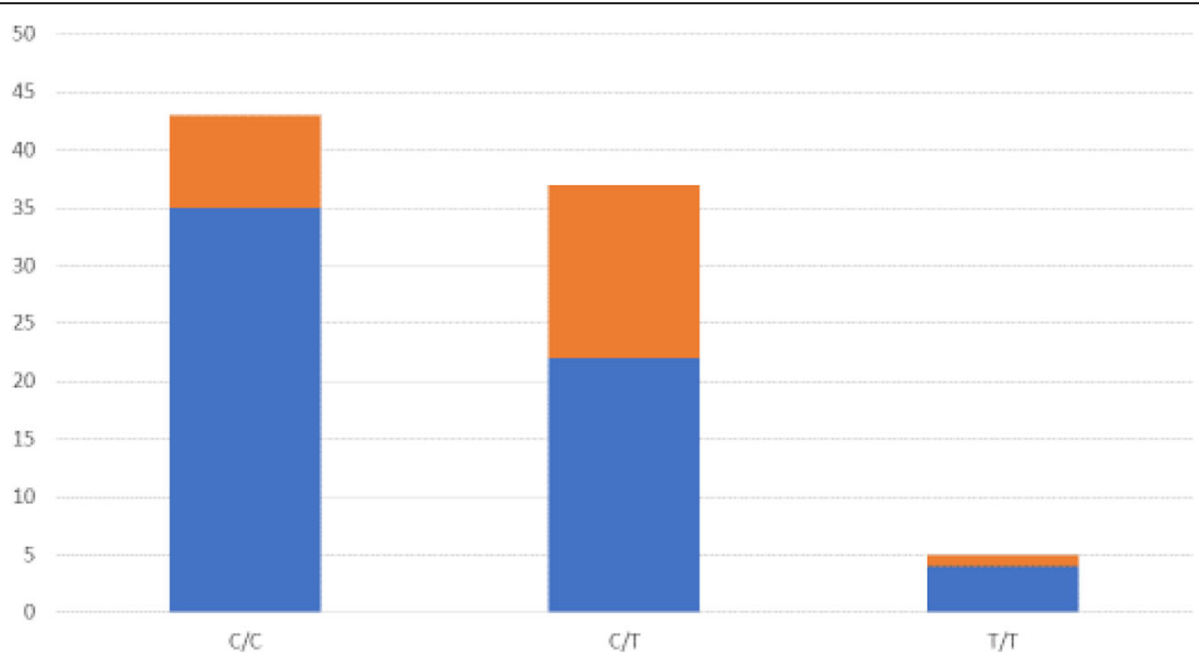

Fig. 2 Genotypic distribution of the c.957C>T (rs6277) SNP, regarding attention problems and hyperactivity. Above: substantial; Below: few 
Table 4 Presence or absence of the T allele of the rs6277 polymorphism of the DRD2 gene, according to sex and ethnicity ${ }^{\mathrm{a}}$, and logistic regression analyses Presence of the T allele (C/T and T/ Absence of the T allele (C/C) p-value $\quad x^{2}$ T)

\begin{tabular}{|c|c|c|c|c|c|c|}
\hline \multicolumn{7}{|l|}{ Sex } \\
\hline Female & $7(35 \%)$ & $13(65 \%)$ & & \multirow[t]{2}{*}{0.140} & \multicolumn{2}{|l|}{2.173} \\
\hline Male & $35(53.8 \%)$ & $30(46.2 \%)$ & & & & \\
\hline \multicolumn{7}{|l|}{ Ethnicity } \\
\hline African & 0 & $8(100 \%)$ & & \multirow[t]{4}{*}{$b$} & \multirow[t]{4}{*}{ b } & \\
\hline $\begin{array}{l}\text { Bi-racial (African and } \\
\text { Caucasian) }\end{array}$ & $8(53.3 \%)$ & $7(46.7 \%)$ & & & & \\
\hline Caucasian & $34(55.7 \%)$ & $27(44.3 \%)$ & & & & \\
\hline Asian $^{a}$ & 0 & $1(100 \%)$ & & & & \\
\hline \multirow[t]{2}{*}{ CBCL 6/18 cluster of symptoms } & Univariate analysis & & & \multicolumn{3}{|c|}{ Final multivariate stepwise analysis } \\
\hline & Odds Ratio & $\begin{array}{l}95 \% \text { Confidence } \\
\text { Interval }\end{array}$ & $\begin{array}{l}p- \\
\text { value }\end{array}$ & $\begin{array}{l}\text { Odds } \\
\text { Ratio }\end{array}$ & $\begin{array}{l}95 \% \text { Confidence } \\
\text { Interval }\end{array}$ & $\begin{array}{l}p- \\
\text { value }\end{array}$ \\
\hline \multicolumn{7}{|c|}{ Challenging and oppositional problems (without $\mathrm{X}$ with alteration) } \\
\hline \multicolumn{7}{|l|}{ Sex } \\
\hline Female/Male & 0.56 & $0.2-1.57$ & 0.267 & - & - & - \\
\hline \multicolumn{7}{|l|}{ Ethnicity } \\
\hline Caucasian/African & 1.46 & $0.33-6.56$ & 0.619 & - & - & - \\
\hline Caucasian/Bi-racial & 2.83 & $0.82-9.76$ & 0.099 & - & - & - \\
\hline \multicolumn{7}{|c|}{ Presence of the T allele of the rs 6277 SNP of the DRD2 gene } \\
\hline No/Yes & 2.78 & $1.15-6.71$ & 0.023 & 2.78 & $1.15-6.71$ & 0.023 \\
\hline \multicolumn{7}{|c|}{ Attention problems and hyperactivity (few $X$ substantial alterations) } \\
\hline \multicolumn{7}{|l|}{ Sex } \\
\hline Female/Male & 0.66 & $0.23-1.92$ & 0.444 & - & - & - \\
\hline \multicolumn{7}{|l|}{ Ethnicity } \\
\hline Caucasian/African & 0.34 & $0.04-2.88$ & 0.320 & - & - & - \\
\hline Caucasian/Bi-racial & 0.96 & $0.27-3.37$ & 0.945 & - & - & - \\
\hline \multicolumn{7}{|c|}{ Presence of the T allele of the rs 6277 SNP of the DRD2 gene } \\
\hline No/Yes & 2.69 & $1.001-7.24$ & 0.050 & 2.69 & $1.001-7.24$ & 0.050 \\
\hline
\end{tabular}

${ }^{\mathrm{a}}$ As there was only one child with Asian ethnicity in the study, this category could not be included in the logistic regression models"; " ${ }^{\mathrm{b}}$ Degrees of freedom (df) = $3 ; x^{2}$ test could not be performed as there were not the minimum number of observations in each cell

symptoms include conditions of difficulties in impulse control, emotion self-control, and behavior regulation [30, 31]. These conditions share a spectrum of externalization associated with personality dimensions named "disinhibition" and inversely, "retraction" [31-33]. The challenging and oppositional problems as well as the attention and hyperactivity problems are common and potentially harmful [31-33]. They frequently occur as comorbidities and share some common etiological factors. The dopaminergic system influences and regulates diverse neuronal and physiological activities such as the sleep/wake cycle, mechanisms of reward and reinforcement, and motivation and learning, besides modulating voluntary movement control $[1,4,34$, 35].. According to Hirvonen et al. (2009), the C/C genotype is associated with low striatal DRD2 availability $(\mathrm{C} / \mathrm{C}<\mathrm{C} / \mathrm{T}$ $<$ TT) [34]. Nevertheless, the authors, in a study of positron emission tomography (PET), found that the $\mathrm{C} / \mathrm{C}$ genotype was associated with high extrastriatal DRD2 binding potential throughout the cortex and the thalamus $(\mathrm{C} / \mathrm{C}>\mathrm{C} / \mathrm{T}>$ $\mathrm{T} / \mathrm{T}$ ) [34]. The authors hypothesized that the putative region-specific features of this SNP could potentially be explained by differential effects of endogenous dopamine on receptor binding, regulation of receptor gene and protein expression or epigenesis, or combination of these factors together with tracer-specific differences [34].

In this study, the presence of the $\mathrm{T}$ allele $(\mathrm{C} / \mathrm{T}$ and $\mathrm{T} / \mathrm{T})$ was significantly associated with clinical attention and hyperactivity problems. Deregulation of the reward system has been proposed as a theoretical model contributing to attention deficit hyperactivity disorder, in which failure in the phasic liberation control of dopamine in the striate would result in injury of the cortico-striatal duct, 
influencing the connection between the cingulate anterior and parietal cortices with the caudate nucleus [36, 37]. According to Dichter et al., dopaminergic function reduction can be implicated with problems in learning and poor behavioral control, but has a reduced influence on rewards related to the behavior [36].

Oppositional defiant disorder involves the violation of others' rights and of the social rules, and is characterized by recurrent patterns of defiant behavior against authority figures, aggressiveness, and violence; it is frequently associated with attention deficit hyperactivity disorder and other kinds of impulsive behaviors [33, 36, 38, 39]. Dopaminergic polymorphisms have been associated with a variety of negative adaptive and antisocial phenotypes $[33,36]$. It has also been suggested that a disability in impulse control is related to a higher tendency toward violence and aggressiveness [33]. The hypo-reactivity of the orbitofrontal cortex and the reduction of dopaminergic function are related to hyposensitivity of the reward system, favoring transgressor behaviors, delinquency, and the abuse of psychoactive substances [39].

A limitation of the present study was the fact that all of the patients were under psychiatric pharmacological treatment during the $\mathrm{CBCL}$ assessment. In addition, the parents' and caregivers' evaluations regarding the children's or adolescents' behaviors tended to focus more on recent problems. The prescription of psychiatric medications as an attempt to decrease externalizing behavioral symptoms can have a positive effect on previously problematic behaviors, and may have influenced the perception in a minority of cases at the time of the CBCL assessment. Nevertheless, the scores of recorded behaviors were high, suggesting that the symptoms were still relevant by the time of the interviews, even with medication use. Another limitation is the small number of participants, which prevents the generalization of the findings. Although preliminary, the findings of this study suggest there may be a potential association of the $\mathrm{T}$ allele of the polymorphism c.957C > T SNP with externalized behavioral conditions. Further studies, with a more representative sample, would also include individuals with the G/G genotype of the rs1799978 polymorphism of the DRD2 gene. This would allow more refined tests for different groups of individuals, including comparisons between those with more than one of the SNPs possibly associated with externalized behavior problems.

The design of this study did not allow to evaluate the effect of the medication on the genotype. The associations found may reflect more treatment response rather than endogenous behavior. Further studies with other designs, including the use of animal models, might aim at exploring the influence of psychopharmacologic treatment on the genotype and on the behavior.

\section{Conclusions}

The association of the $\mathrm{T}$ allele of the polymorphism $\mathrm{c}$. 957C > T (rs6277) with disruptive/aggressive symptoms, and problems of behavior, oppositional defiance, and attention/hyperactivity suggest that $D R D 2$ gene expression changes can help with the identification of genetically associated behavioral and mental phenotypes. New studies analyzing the possible longitudinal association between these polymorphisms and the symptoms of more common occurrence in adults (manic psychotic, depressive symptoms) are encouraged to evaluate these relationships in more detail. In particular, more in-depth study of the SNPs are required for applications in not only improving diagnoses but also for preventive medicine. A broader view of the field of externalized behavioral conditions with respect to personalized medicine taking into account different genetic susceptibilities may facilitate the development of new drugs, as well as provide new ways of prescribing existing drugs, in a genetically oriented way according to the needs of each patient.

\section{Abbreviations \\ CBCL: Child Behavior Checklist; CBMEG: Molecular Biology and Genetics Engineering Center; DNA: Deoxyribonucleic acid; DRD2: Dopamine D2 receptor gene; DSM: Diagnostic and Statistical Manual of Mental Disorders; FAPESP: São Paulo Research Foundation; PET: Positron Emission Tomography; RNA: Ribonucleic acid; SNP: Single Nucleotide Polymorphisms; \\ Unicamp: University of Campinas}

\section{Acknowledgments}

The authors thank all participants for their cooperation in our study and the support of São Paulo Research Foundation (FAPESP).

\section{Funding}

This study was supported by São Paulo Research Foundation (FAPESP-Process $n^{\circ}$ 2012/14005-1).

\section{Availability of data and materials}

For access to the data in this paper, interested researchers may contact the corresponding author via email: dr.osmar.psiq@gmail.com.

\section{Authors' contributions}

ASJ, GGJ and PD designed the study. OHDT and LAP performed the data collection. TBH and MPM coordinated the molecular genetics work. OHDT, ASJ, EHRVC, GGJ and PD performed data analyses. OHDT, ASJ, GGJ and PD were responsible for manuscript writing. All the authors contributed to discuss the results. And all authors read and approved the final manuscript.

\section{Competing interest}

The authors declare that they have no competing interests.

Ethics approval and consent to participate

This study was approved by Research Ethics Committee of the Unicamp (Concurring opinion 44,199, Certificate of Presentation for Ethic Appreciation 04369612.8.0000.5404; 26.06.2012). All parents/caregivers of the subjects who participated in the study provided written informed consent. Besides the written informed consent provided by the parents/caregivers, all the children and adolescents also provided oral consent and assent to participate.

\section{Publisher's Note}

Springer Nature remains neutral with regard to jurisdictional claims in published maps and institutional affiliations. 


\section{Author details}

Department of Psychiatry - Faculty of Medical Sciences (FCM), State University of Campinas (Unicamp), Campinas, SP, Brazil. ${ }^{2}$ Laboratory of Human Genetics - Center for Molecular Biology and Genetic Engineering (CBMEG), Unicamp, Campinas, SP, Brazil. ${ }^{3}$ Growth and Development Laboratory - Center for Investigation in Pediatrics (CIPED), FCM - Unicamp, Campinas, SP, Brazil. ${ }^{4}$ Department of Pediatrics - Pediatric Endocrinology Unit, FCM - Unicamp, Campinas, SP, Brazil. ${ }^{5}$ Rua Tessália Vieira de Camargo, 126, Cidade Universitária Zeferino Vaz - Campinas, São Paulo ZIP Code: 13083-887, Brazil.

\section{Received: 16 July 2017 Accepted: 19 April 2018}

\section{Published online: 02 May 2018}

\section{References}

1. Missale C, Nash SR, Robinson SW, Jaber M, Caron MG. Dopamine receptors: from structure to function. Physiol Rev. 1998;78(1):189-225. https://doi.org/ 10.1154/physrev.1998.78.1.189.

2. Hirvonen MM, Laakso A, Någren K, Rinne JO, Pohjalainen T, Hietala J. C957T polymorphism of dopamine D2 receptor gene affects striatal DRD2 in vivo availability by changing the receptor affinity. Synapse. 2009;63(10):907-12. https://doi.org/10.1002/syn.20672.

3. Beaulieu JM, Gainetdinov RR. The physiology, signaling, and pharmacology of dopamine receptors. Pharmacol Rev. 2011;63(1):182-217. https://doi.org/ 10.1124/pr.110.002642.

4. Rangel-Barajas C, Coronel I, Florán B. Dopamine receptors and neurodegeneration. Aging Dis. 2015;6(5):349-68. https://doi.org/10. 14336/AD.2015.0330.

5. Colzato LS, van den Wildenberg WPM, Van der Does AJ, Hommel B. Genetic markers of striatal dopamine predict individual differences in dysfunctional, but not functional impulsivity. Neuroscience. 2010;170(3):782-8. https://doi. org/10.1016/j.neuroscience.2010.07.050.

6. Colzato LS, van den Wildenberg WPM, Hommel B. The genetic impact (C957T-DRD2) on inhibitory control is magnified by aging. Neuropsychologia. 2013;51(7):1377-81. https://doi.org/10.1016/j.neuropsychologia.2013.01.014.

7. Wallis D, Russell HF, Muenke M. Review: genetics of attention deficit/ hyperactivity disorder. J Pediatr Psychol. 2008;33(10):1085-99. https://doi. org/10.1093/jpepsy/jsn049.

8. Short Genetic Variations: rs6277. http://www.ncbi.nlm.nih.gov/SNP/snp_ref. cgi?rs=6277\&pt=1ZifN3On0TUebcc8qblSrjfYn-wEZ2axp3ac9nm5hgmkv. Accessed 2 Apr 2016.

9. White MJ, Lawford BR, Morris CP, Young RM. Interaction between DRD2 C957T polymorphism and an acute psychosocial stressor on reward-related behavioral impulsivity. Behav Genet. 2009;39(3):285-95. https://doi.org/10. 1007/s10519-008-9255-7.

10. Hirvonen M, Laakso A, Någren K, Rinne JO, Pohjalainen T, Hietala J. C957T polymorphism of the dopamine D2 receptor (DRD2) gene affects striatal DRD2 availability in vivo. Mol Psychiatry. 2004;9(12):1060-1. https://doi.org/ 10.1038/sj.mp.4001561.

11. Hänninen K, Katila H, Kampman O, Anttila S, Illi A, Rontu R, et al. Association between the C957T polymorphism of the dopamine D2 receptor gene and schizophrenia. Neurosci Lett. 2006;407(3):195-8. https://doi.org/10.1016/j.neulet. 2006.08.041.

12. Duan J, Wainwright MS, Comeron JM, Saitou N, Sanders AR, Gelernter J, et al. Synonymous mutations in the human dopamine receptor D2 (DRD2) affect mRNA stability and synthesis of the receptor. Hum Mol Genet. 2003; 12(3):205-16. https://doi.org/10.1093/hmg/ddg055.

13. Zhang JP, Malhotra AK. Pharmacogenetics and antipsychotics: therapeutic efficacy and side effects prediction. Expert Opin Drug Metab Toxicol. 2011; 7(1):9-37. https://doi.org/10.1517/17425255.2011.532787.

14. Chan TWS, Bates JE, Lansford JE, Dodge KA, Pettit GS, Dick DM, et al. Impulsivity and genetic variants in DRD2 and ANKK1 moderate longitudinal associations between sleep problems and overweight from ages 5 to 11. Int J Obes. 2014;38(3):404-10. https://doi.org/10.1038/ijo.2013.123.

15. Manual for the ASEBA Brief Problem monitor. http://www.aseba.org/ Brief Problem Monitor Manual.pdf. Accessed 3 Apr 2016.

16. Achenbach TM, Rescorla LA. Manual for the ASEBA School-Age Forms \& Profiles. Burlington: University of Vermont, Research Center for Children, Youth, \& Families; 2001.

17. Bordin IAS, Mari JJ, Caeiro MF. Validação da versão brasileira do "Child Behavior Checklist" (CBCL) (Inventário de Comportamentos da Infância e
Adolescência): dados preliminares / [Validation of the Brazilian version of the Child Behavior Checklist (CBCL): preliminay data]. Rev ABP-APAL. 1995; 17(2):55-66.

18. Wielewicki A, Gallo AE, Grossi R. Instrumentos na prática clínica: CBCL como facilitador da análise funcional e do planejamento da intervenção. [Clinical practice instruments: $\mathrm{CBCL}$ as a functional analysis and intervention planning facilitator]. Temas em Psicol. 2011;19(2):513-23.

19. Gorenstein C, Wang YP, Hungerbuhler I. Instrumentos de Avaliação Em Saúde Mental. [Mental Health Assessment Tools] Porto Alegre, Brazil: Artmed; 2016.

20. Paula CS, Coutinho ES, Mari JJ, Rohde LA, Miguel EC, Bordin IA. Prevalence of psychiatric disorders among children and adolescents from four Brazilian regions. Rev Bras Psiquiatr. 2015;37(2):178-9. https://doi.org/10.1590/15164446-2014-1606.

21. Sambrook J, Fritsh EF, Maniatis T. Molecular cloning: a laboratory manual: Cold Spring Cold Spring Harbor, NY, EUA: Harbor Laboratory Press (2nd edition); 1989

22. Validation Using SDS Software Version 1.2.3 on the Applied Biosystems 7500 Real-Time PCR System and the ABI PRISM ${ }^{\oplus} 7000$ Sequence Detection System. http://www3.appliedbiosystems.com/cms/groups/applied_markets_support/ documents/generaldocuments/cms_041395.pdf. Accessed 10 Mar 2018.

23. Haploview Broad Institute of MIT and Harvard. https://www.broadinstitute. org/scientific-community/science/programs/medical-and-populationgenetics/haploview/haploview. Accessed 10 Mar 2018.

24. Barrett JC, Fry B, Maller J, Daly MJ. Haploview: analysis and visualization of LD and haplotype maps. Bioinformatics. 2005;21(2):263-5. https://doi.org/10. 1093/bioinformatics/bth457.

25. 1000 Genomes browser: Homo sapiens - Explore this variation - rs6277 (SNP). http://grch37.ensembl.org/Homo_sapiens/Nariation/Explore?r=11:113282959113283959; $v=r s 6277 ; v d b=$ variation;vf=6020. Accessed 2 Apr 2016.

26. HapMap Data Rel 28 Phase II+III, August10, on NCBI B36 assembly, dbSNP b126: chr11:112851561..112851561. http://hapmap.ncbi.nlm.nih.gov/cgi-perl/ gbrowse/hapmap28_B36/\#search. Accessed 11 Apr 2016.

27. 1000 Genomes browser: Homo sapiens - Explore this variation - rs1799978 (SNP). http://grch37.ensembl.org/Homo_sapiens/Variation/Explore?r=11: 113345851-113346851;v=rs1799978; vdb=variation;vf=1245332. Accessed 2 Apr 2016.

28. Pena SDJ, di Pietro G, Fuchshuber-Moraes M, Genro JP, Hutz MH, FdeS K, et al. The genomic ancestry of individuals from different geographical regions of Brazil is more uniform than expected. PLoS One. 2011;6(2): e17063. https://doi.org/10.1371/journal.pone.0017063.

29. Rodrigues de Moura R, Coelho AVC, de Queiroz Balbino V, Crovella S, Brandão LAC. Meta-analysis of Brazilian genetic admixture and comparison with other Latin America countries. Am J Hum Biol. 2015;27(5):674-80. https://doi.org/10.1002/ajhb.22714.

30. Goodman R, Scott S. Child and Adolescent Psychiatry. Hoboken: WileyBlackwell (3rd edition); 2012.

31. Martel MM, Nikolas M, Jernigan K, Friderici K, Nigg JT. Diversity in pathways to common childhood disruptive behavior disorders. J Abnorm Child Psychol. 2012;40(8):1223-36. https://doi.org/10.1007/s10802-012-9646-3.

32. Aebi M, van Donkelaar MMJ, Poelmans G, Buitelaar JK, Sonuga-Barke EJ, Stringaris A, et al. Gene-set and multivariate genome-wide association analysis of oppositional defiant behavior subtypes in attention-deficit/ hyperactivity disorder. Am J Med Genet B Neuropsychiatr Genet. 2015; 171(5):573-88. https://doi.org/10.1002/ajmg.b.32346.

33. Beaver KM, Wright JP, DeLisi M, Walsh A, Vaughn MG, Boisvert D, et al. A gene $x$ gene interaction between DRD2 and DRD4 is associated with conduct disorder and antisocial behavior in males. Behav Brain Funct. 2007; 3:30. https://doi.org/10.1186/1744-9081-3-30.

34. Hirvonen MM, Lumme V, Hirvonen J, Pesonen U, Någren $K$, Vahlberg $T$, et al. C957T polymorphism of the human dopamine D2 receptor gene predicts extrastriatal dopamine receptor availability in vivo. Prog NeuroPsychopharmacology Biol Psychiatry. 2009;33(4):630-6. https://doi.org/10. 1016/j.pnpbp.2009.02.021.

35. Huertas E, Bühler K-M, Echeverry-Alzate V, Giménez T, López-Moreno JA C957T polymorphism of the dopamine D2 receptor gene is associated with motor learning and heart rate. Genes Brain Behav. 2012;11(6):677-83. https://doi.org/10.1111/j.1601-183X.2012.00793.x.

36. Dichter GS, Damiano CA, Allen JA. Reward circuitry dysfunction in psychiatric and neurodevelopmental disorders and genetic syndromes: animal models and clinical findings. J Neurodev Disord. 2012:4(1):19. https:// doi.org/10.1186/1866-1955-4-19. 
37. Comings DE, Blum K. Reward deficiency syndrome: genetic aspects of behavioral disorders. Prog Brain Res. 2000;126:325-41. https://doi.org/10, 1016/50079-6123(00)26022-6.

38. Vermeulen KM, Jansen DEMC, Buskens E, Knorth EJ, Reijneveld SA. Serious child and adolescent behaviour disorders; a valuation study by professionals, youth and parents. BMC Psychiatry. 2017;17:208. https://doi. org/10.1186/s12888-017-1363-6.

39. Matthys W, Vanderschuren LJMJ, Schutter DJLG. The neurobiology of oppositional defiant disorder and conduct disorder: altered functioning in three mental domains. Dev Psychopathol. 2013;25(1):193-207. https://doi. org/10.1017/S0954579412000272.

Ready to submit your research? Choose BMC and benefit from:

- fast, convenient online submission

- thorough peer review by experienced researchers in your field

- rapid publication on acceptance

- support for research data, including large and complex data types

- gold Open Access which fosters wider collaboration and increased citations

- maximum visibility for your research: over $100 \mathrm{M}$ website views per year 